\title{
Generation of human chronic wasting disease in transgenic mice
}

\author{
Zerui Wang ${ }^{1 \dagger}$, Kefeng Qin ${ }^{2 \dagger}$, Manuel V. Camacho ${ }^{1 \dagger}$, Ignazio Cali ${ }^{1 \dagger}$, Jue Yuan ${ }^{1}$, Pingping Shen ${ }^{1}$, Justin Greenlee ${ }^{3}$, \\ Qingzhong Kong ${ }^{1,4,5,6^{*}}$, James A. Mastrianni ${ }^{2^{*}}$ and Wen-Quan Zou ${ }^{1,4,5,6^{*}}$
}

\begin{abstract}
Chronic wasting disease (CWD) is a cervid prion disease caused by the accumulation of an infectious misfolded conformer $\left(\mathrm{PrP}^{\mathrm{SC}}\right)$ of cellular prion protein $\left(\mathrm{PrP}^{\mathrm{C}}\right)$. It has been spreading rapidly in North America and also found in Asia and Europe. Although bovine spongiform encephalopathy (i.e. mad cow disease) is the only animal prion disease known to be zoonotic, the transmissibility of CWD to humans remains uncertain. Here we report the generation of the first CWD-derived infectious human $\mathrm{PrP}^{\mathrm{Sc}}$ by elk CWD PrPSc-seeded conversion of $\mathrm{PrPC}^{\mathrm{C}}$ in normal human brain homogenates using in vitro protein misfolding cyclic amplification (PMCA). Western blotting with human PrP selective antibody confirmed that the PMCA-generated protease-resistant $\operatorname{PrP}^{\mathrm{SC}}$ was derived from the human PrPC substrate. Two lines of humanized transgenic mice expressing human PrP with either Val or Met at the polymorphic codon 129 developed clinical prion disease following intracerebral inoculation with the PMCA-generated CWD-derived human $\operatorname{PrP}^{\mathrm{Sc}}$. Diseased mice exhibited distinct $\mathrm{PrP}^{\mathrm{Sc}}$ patterns and neuropathological changes in the brain. Our study, using PMCA and animal bioassays, provides the first evidence that CWD PrPSC can cross the species barrier to convert human PrPC into infectious PrPSC that can produce bona fide prion disease when inoculated into humanized transgenic mice.
\end{abstract}

Keywords: Chronic wasting disease (CWD), Prion disease, Prions $\left(\mathrm{PrP}^{\mathrm{SC}}\right)$, Cellular prion protein $\left(\mathrm{PrP}^{\mathrm{C}}\right)$, Serial protein misfolding cyclic amplification (SPMCA)

\section{Introduction}

Prion diseases are fatal transmissible spongiform encephalopathies of humans and animals characterized by the accumulation of the infectious prion protein $\left(\mathrm{PrP}^{\mathrm{Sc}}\right)$ that is derived from its cellular isoform $\left(\operatorname{PrP}^{\mathrm{C}}\right)$ through a structural transition [32]. It is known that prion diseases are less transmissible across species because of

\footnotetext{
*Correspondence: qxk2@case.edu; jmast@neurology.bsd.uchicago.edu; wxz6@case.edu

†Zerui Wang, Kefeng Qin, Manuel V. Camacho and Ignazio Cali Contributed equally to this work

1 Department of Pathology, Case Western Reserve University School of Medicine, Cleveland, OH 44106, USA

${ }^{2}$ Department of Neurology and Center for Comprehensive Care and Research On Memory Disorders, The University of Chicago Pritzker School of Medicine, Chicago, IL, USA

Full list of author information is available at the end of the article
}

species barrier associated largely with differences in each host's PrP sequences [31]. However, bovine spongiform encephalopathy (BSE, commonly named mad cow disease) has been well-documented to cause variant Creutzfeldt-Jakob disease (vCJD) in humans [8, 13, 41], the first proven zoonotic prion disease. The outbreak of mad cow disease and its zoonotic transmissibility raise concerns about the potential public health threat from other animal-derived prion diseases.

Chronic wasting disease (CWD) is the most contagious of all prion diseases, and it is endemic in North America, having spread to 26 US states and 3 Canadian provinces. The disease has also been found in South Korea and most recently in Europe [6, 38]. The CWD prevalence rates among free-ranging cervids are as high as $40 \%$ in some areas of Colorado, Wyoming, and 
Wisconsin of the United States, where large amounts of venison are consumed [21, 30,36]. Moreover, prions are readily shed from infected cervids through urine, feces, saliva, and carcasses. Prions in these excreta and bodies remain stable and infectious in the environment for many years. Thus, CWD poses potential risks to public health in North America. However, the zoonotic potential of CWD remains uncertain. On the one hand, there has been no published epidemiological evidence to support CWD transmissibility to humans. Published transmission studies so far have consistently failed to transmit the CWD agent to "humanized" transgenic ( $\mathrm{Tg}$ ) mice expressing human $\operatorname{PrP}[20,23,37]$. Moreover, Race and co-workers have reported that the non-human primate Cynomolgus macaques were not susceptible to CWD [33-35]. On the other hand, Barria and co-workers observed that human $\operatorname{PrP}^{\mathrm{C}}$ from normal humanized transgenic $(\mathrm{Tg})$ mouse brains could be converted by CWD PrP ${ }^{S c}$ into proteinase $\mathrm{K}(\mathrm{PK})$-resistant $\operatorname{PrP}\left(\mathrm{PrP}^{\text {res }}\right)$, albeit at low to moderate conversion efficiencies [3, 4]. In addition, squirrel monkeys have been found to be highly susceptible to CWD from white-tailed deer, mule deer, and elk after either intracerebral or oral challenges $[3,4$, 27]. Furthermore, a recent international study observed an atypical phenotype in Cynomolgus macaques after challenge with CWD prions orally or intracerebrally: the affected animals showed minimal $\mathrm{PrP}^{\mathrm{Sc}}$ in the CNS by immunohistochemistry staining and positive prion seeding activity by RT-QuIC and PMCA assays [14]. These conflicting experimental data and observations preclude a clear answer on whether CWD prions are zoonotic at this point. In order to demonstrate that CWD prions are zoonotic, it will be critical to search for direct evidence that CWD prions are capable of converting human brain $\operatorname{PrP}^{\mathrm{C}}$ into infectious $\operatorname{PrP}^{\mathrm{Sc}}$, that $\mathrm{CWD}$ prions can infect Tg mice expressing human PrP, and that ultimately the first cases of CWD transmissions to humans are identified. In addition, generation of experimental human CWD prions will also provide critical clues for the detection and diagnosis of acquired human CWD cases if and when they occur.

It is worth noting that the annual number of sporadic CJD (sCJD) cases in the USA has increased, with the total number of suspected and confirmed sCJD cases rising from 284 in 2003 to 511 in 2017 (https://www.cdc.gov/ prions/cjd/occurrence-transmission.html). The greatly enhanced CJD surveillance and an aging population in the USA certainly contributed to the observed increase in annual SCJD case numbers in recent years, but the possibility cannot be excluded that some of the increased sCJD prevalence is linked to CWD exposure.

In the present study, using serial protein misfolding cyclic amplification (sPMCA) assay we generate $\operatorname{PrP}^{\mathrm{Sc}}$ by seeding CWD prions in normal human brain homogenates. Importantly, we reveal that two lines of humanized Tg mice expressing human PrP-129VV and 129MM develop prion diseases upon intracerebral inoculation of the abnormal PrP generated by sPMCA. We believe that our study provides the first opportunity to dissect the clinical, pathological and biochemical features of the CWD-derived human prion disease in two lines of humanized Tg mice expressing two major human PrP genotypes, respectively.

\section{Materials and methods \\ Reagents and antibodies}

Proteinase K (PK) was purchased from Sigma Chemical Co. (St. Louis, MO). Reagents for enhanced chemiluminescence (ECL Plus) were from GE Healthcare. Anti-PrP antibody 3F4 against human PrP residues 107-112 [18, 45] and horseradish peroxidase-conjugated sheep antimouse IgG were purchased from Millipore Sigma (Burlington, MA).

\section{Preparation of brain samples}

Frozen non-CJD human brain tissues with $\operatorname{PrP}^{\mathrm{C}}-129 \mathrm{MM}$ or $\operatorname{PrP}^{\mathrm{C}}-129 \mathrm{VV}$ were collected at autopsy and maintained at $-80{ }^{\circ} \mathrm{C}$ until used as substrates in PMCA. Brain tissues from uninfected humanized TgMM or $\mathrm{TgVV}$, cervidized TgDeer (kindly provided by Glenn Telling, Ph.D., Colorado State University), or hamsters were also used as substrates in serial PMCA as controls. The samples were rinsed with PBS three times to avoid blood contamination before homogenization. For sequencing of the functional cervid PrP genes, genomic DNA was purified from frozen cervid brain tissues using standard phenol-chloroform extraction, and the coding region from the $\operatorname{PrP}$ genes was amplified by PCR using DePrP223 (ACACCC TC-TTTATTTTGCAG) and DePrP224 (AGAAGATAA TGAAAACAGGAAG) primers. The PCR products were cloned into pstBlue-1. Purified PCR product and multiple clones from each cervid DNA sample were subjected to sequencing by MCLAB (South San Francisco, CA, USA) using the same primers. The elk samples came from elk with different PRNP genotypes: \#1, \#2, \#3, and \#4 (CWDnegative) were PrP-132MM; \#5, \#6 and \#7 were PrP132ML; and \#8 was PrP-132LL. The genotype of the deer CWD (dCWD) isolate \#9 was not available. Elk samples \#1 through \#7 and deer sample \#9 were from captive animals in the terminal stages of disease and originated from the western United States. Elk sample \#8 was from an elk with the PrP-132LL genotype that was experimentally inoculated with brain homogenate from a farmed elk of the same genotype.

Brain tissues were homogenized with a mini-Beads Beater in conversion buffer containing $150 \mathrm{mM} \mathrm{NaCl}$, 
1\% Triton X-100, $8 \mathrm{mM}$ EDTA and a complete protease inhibitor in PBS without $\mathrm{Ca}^{2+}$ and $\mathrm{Mg}^{2+}$ for a $10 \%$ brain homogenate. The samples were then centrifuged at $500 \mathrm{~g}$ for $5 \mathrm{~min}$. The supernatant (S1) was transferred to a clean tube for future use. Brain homogenates $(10 \%$, weight/volume) from elk $(\mathrm{n}=7, \# 1-\# 3, \# 5-\# 8)$ and deer $(\mathrm{n}=1, \# 9)$ with CWD or non-CWD $(\mathrm{n}=1, \# 4)$ were prepared as PMCA seeds in $1 \times$ lysis buffer containing [ $10 \mathrm{mM}$ Tris$\mathrm{HCl}, 150 \mathrm{mM} \mathrm{NaCl}, 0.5 \%$ Nonidet P-40 (NP-40), 0.5\% deoxycholate, $5 \mathrm{mM}$ ethylenediaminetetraacetic acid (EDTA), pH 7.4]. For prion-infected mouse brain tissues, $10 \%$ brain homogenates were prepared in $1 \times$ lysis buffer and the brain homogenates were treated with designated amounts of PK prior to Western blotting probing with 3F4. To prepare the detergent-soluble (S2) and detergentinsoluble (P2) fractions, the PMCA products or $10 \%$ normal brain homogenate (substrate, in conversion buffer) were mixed with an equal volume of $2 \times$ lysis buffer and then subjected to ultracentrifugation at 100,000 $\mathrm{g}$ for $1 \mathrm{~h}$ at $4{ }^{\circ} \mathrm{C}$. The supernatant was transferred into a clean tube as the $\mathrm{S} 2$, whereas the pellet was resuspended in $1 \times$ lysis buffer as the P2 at the volume equal to that of S2.

\section{Protein misfolding cyclic amplification (PMCA)}

The preparation of PrP seeds and substrates, as well as PMCA, were conducted as previously described $[11,40]$ and above. Each seed was diluted in the substrate at a ratio of 1:100 $(1 \mu \mathrm{L}$ seeds $+99 \mu \mathrm{L}$ substrates containing $50 \mu \mathrm{g} / \mathrm{mL}$ heparin) into a $200 \mu \mathrm{L}$ PCR tube with 1 PTFE beads (diameter 3/32") (Teflon, APT, RI). $20 \mu \mathrm{L}$ of each mixture was taken and kept at $-20{ }^{\circ} \mathrm{C}$ as a non-PMCA control. The remaining mixture was subjected to serial PMCA (sPMCA). Each cycle was comprised of a $20 \mathrm{~s}$ elapse time of sonication at amplitude 85 (250 watts; Misonix S3000 sonicator) followed by an incubation period of $29 \mathrm{~min} 40 \mathrm{~s}$ at $37^{\circ} \mathrm{C}$. Each round of sPMCA consisted of 96 cycles. For subsequent sPMCA rounds, $10 \mu \mathrm{L}$ sample was taken from the last cycle of the immediate preceding round and placed into $90 \mu \mathrm{L}$ fresh normal brain substrates to start a new round of amplifications.

\section{Prion-inoculation and monitoring of humanized transgenic mice}

Two lines of humanized transgenic mice were used in this study for assessing the infectivity of the PMCAinduced CWD-derived human $\operatorname{PrP}^{\mathrm{Sc}}$. Humanized TgMM (also named $\mathrm{Tg} 40 \mathrm{~h}$ ) and $\mathrm{TgVV}$ (also termed Tg1307, derived from $\mathrm{Tg} 152$ ) mice expressing wild-type human PrP carrying either $129 \mathrm{M}$ or $129 \mathrm{~V}$ polymorphism without endogenous mouse PrP as previously described $[20$, 42] were used in this study. The PMCA product seeded by \#6 CWD prion isolate was diluted into $1 \%$ human brain homogenate in $1 \times$ PBS before inoculation. After anesthetization of $\mathrm{Tg}$ mice with isoflurane, $30 \mu \mathrm{L}$ of the diluted PMCA product was injected intracerebrally into each mouse with a 26-gauge needle as described previously [20, 42]. After intracerebral inoculations, the animals were monitored at least 3 times per week for symptoms such as coarse coat, waddling gait, hunched back, tail plasticity, and bradykinesia. Within 2-3 d days after presentation of clear symptoms or at death, the brain was removed and one-half brain was frozen for Western blotting of $\operatorname{PrP}^{\mathrm{Sc}}$, and the other half was fixed in formalin for histology and immunohistochemistry analysis as described below.

\section{Western blotting}

PMCA brain samples were subjected to treatment with PK at $100 \mu \mathrm{g} / \mathrm{mL}$ for $70 \mathrm{~min}$ at $45^{\circ} \mathrm{C}$ with agitation prior to Western blotting. Samples were resolved on 15\% Tris$\mathrm{HCl}$ Criterion pre-cast gels (Bio-Rad) for SDS-PAGE as described previously [44]. The proteins on the gels were transferred to Immobilon-P membrane polyvinylidene fluoride membrane (PVDF, Millipore) for $2 \mathrm{~h}$ at $350 \mathrm{~mA}$. For probing of $\mathrm{PrP}$, the membranes were incubated for $2 \mathrm{~h}$ at room temperature with anti-PrP antibody 3F4 at $1: 40,000$ as the primary antibody. Following incubation with horseradish peroxidase-conjugated sheep antimouse IgG at 1:5,000, the PrP bands were visualized on Kodak film (Millipore Sigma) by ECL Plus as described by the manufacturer (GE Healthcare). For detection of the PK-resistant $\operatorname{PrP}^{\mathrm{Sc}}$ in the frozen brain tissues of infected Tg mice, $50 \mu \mathrm{g} / \mathrm{mL}$ of PK or designated amounts of PK were used as indicated in each experiment at $37{ }^{\circ} \mathrm{C}$ for $1 \mathrm{~h}$.

\section{Histology, immunohistochemistry and lesion profiles}

Histological and immunohistochemical evaluations were carried out on sagittal brain levels at approximately $3.12 \mathrm{~mm}$ and $1.56 \mathrm{~mm}$ to the midline as previously described $[9,40]$. Paraffin-embedded sections were stained with hematoxylin-eosin (H\&E) or immunohistochemistry (IHC) probed with the 3F4 antibody at 1:1,500 dilution, 10\% GVM and then processed with the DAB detection kit as described by the manufacturer. Lesion profiles were generated following semi-quantitative evaluation of spongiform degeneration (SD) severity, which was rated on a 0 to 3 scale on H\&E-stained Sects. (0: not detectable; 1 : mild, 2 : moderate, and 3: severe). The eight brain regions examined included the cerebral cortex (CC), hippocampus (HI), basal ganglia (BG), thalamus $(\mathrm{TH})$, dorsal $(\mathrm{d})$ and ventral $(\mathrm{v})$ midbrain $(\mathrm{MB})$, inferior brainstem (BS.i), and cerebellum (CE). 


\section{Statistical analysis}

The differences in incubation times between $\mathrm{TgVV}$ and TgMM mice inoculated with sPMCA-induced CWDderived human $\operatorname{PrP}^{\mathrm{Sc}}$ as well as differences in lesion severity between different mice were statistically analyzed using Student's $T$-test to obtain $p$ values for comparisons between two groups.

\section{Results}

\section{Generation of CWD-derived human PrP ${ }^{\text {Sc }}$ by PMCA}

To determine whether CWD prions from affected cervid animal brains can convert $\operatorname{PrP}^{\mathrm{C}}$ from the normal human brain into $\operatorname{PrP}^{\mathrm{Sc}}$, we conducted protein misfolding cyclic amplification (PMCA) assays. These PMCA assays used brain homogenates of 3 individual CWD elk (CWD prion isolates \#1, \#2, or \#3) as the prion seeds and brain homogenates from three non-CJD subjects as the substrates, respectively. These non-CJD subjects included two cases homozygous for methionine (M) at polymorphic codon 129 of the $\operatorname{PrP}$ gene (PrP-129MM) termed MM\#1 and MM\#2, and a case homozygous for valine (V) at codon 129 (PrP-129VV) designated VV\#1. After 1 round of PMCA, Western blotting showed PrP ${ }^{\text {res }}$ in 2 of 3 PMCA products seeded with CWD brain homogenates elk \#1 and \#2, but not elk \#3 or the negative control elk \#4, with the VV\#1 substrate but not the MM\#1 or MM\#2 substrates (Fig. 1a). Since we used the anti-PrP monoclonal antibody 3F4 that is specific for human PrP but not cervid PrP as shown in Additional file 1: Fig. S1, we conclude that all detected PK-resistant $\operatorname{PrP}$ is exclusively human $\operatorname{PrP}^{\text {res }}$ instead of cervid $\operatorname{PrP}^{\mathrm{Sc}}$, excluding the possibility that the detected PK-resistant $\mathrm{PrP}^{\mathrm{res}}$ in the PMCA products could be the CWD PrP ${ }^{\mathrm{Sc}}$ seeds themselves rather than newly-converted $\mathrm{PrP}^{\text {res }}$ from human $\mathrm{PrP}^{\mathrm{C}}$.

To rule out the possibility that the detected $\operatorname{PrP}^{\text {res }}$ was de novo $\operatorname{PrP}^{\text {res }}$ generated from the $\operatorname{PrP}^{\mathrm{C}}$ substrate itself by PMCA, we conducted serial PMCA (sPMCA) with

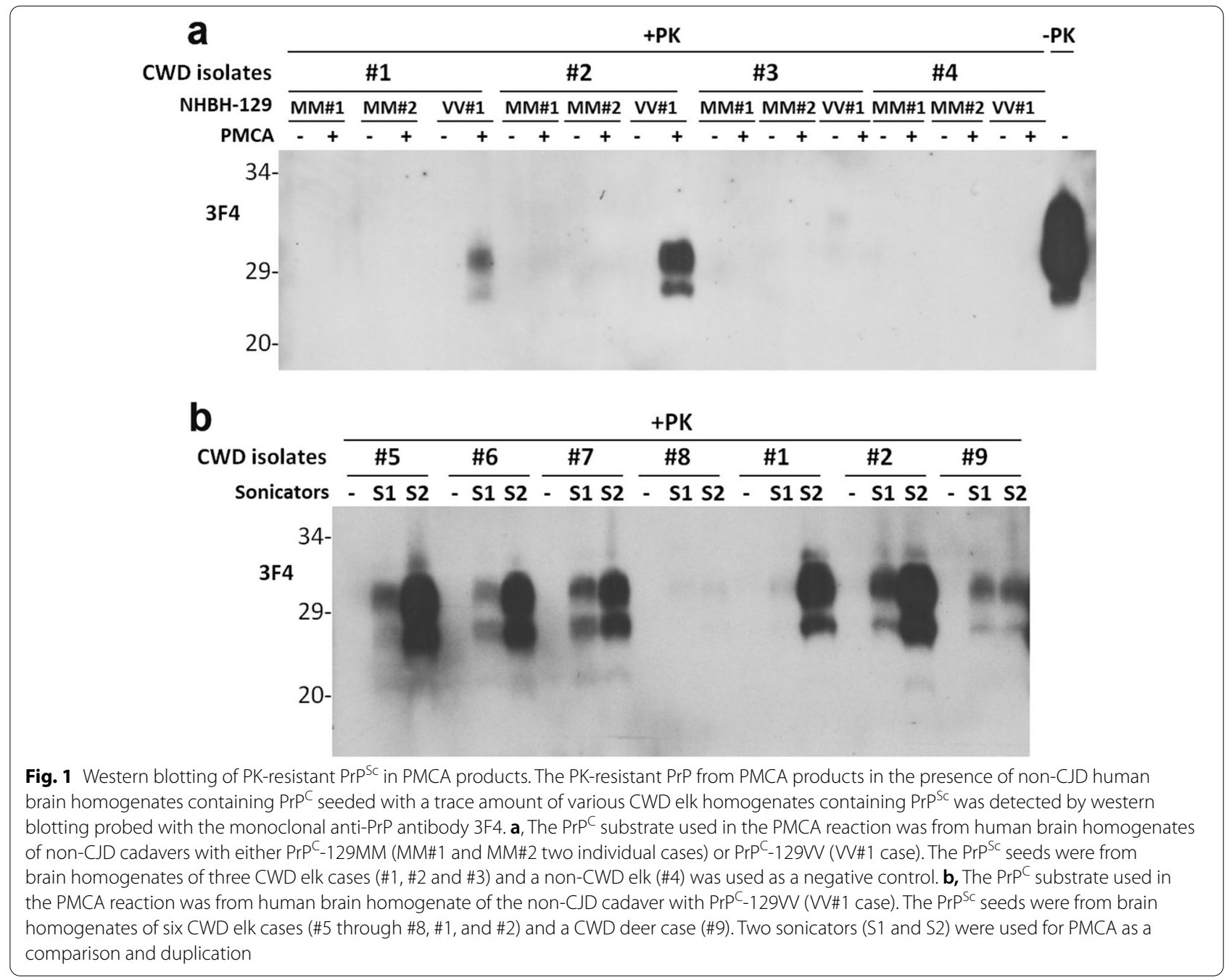


normal brain homogenates in the absence of CWD $\mathrm{PrP}^{\mathrm{Sc}}$ seeds (Additional file 1: Fig. S2). No PrP ${ }^{\text {res }}$ was detected in MM\#1 and VV\#1 after 12 rounds of sPMCA while it was detected in $\mathrm{MM \# 2}$ after 6 or more rounds and in VV\#2 after 9 or more rounds of sPMCA (Additional file 1: Fig. S2a, c, d). TgVV mouse brain homogenates showed no de novo PrPres generation after 12 rounds while TgMM was observed to generate de novo PrPres after 3 or more rounds of sPMCA (Additional file 1: Fig. S2b, c, d). In addition, normal hamster brain homogenates showed generation of de novo PrP ${ }^{\text {res }}$ after 6 or more rounds of sPMCA (Additional file 1: Fig. S1c) and no de novo $\operatorname{PrP}^{\text {res }}$ was found in TgDeer brain homogenates after 4 rounds of sPMCA (Additional file 1: Fig. S2b).

Using the same PMCA approach, we further examined the convertibility of human brain $\operatorname{PrP}^{\mathrm{C}}-129 \mathrm{VV}$ (VV\#2) by $\mathrm{PrP}^{\mathrm{Sc}}$ from $7 \mathrm{CWD}$ cases that were composed of $6 \mathrm{CWD}$ elks (\#1, \#2, \#5-\#8) and 1 CWD deer (\#9). The PMCA assays were performed with two sonicators (S1 and S2) for comparison and duplication. We observed that $\mathrm{PrP}^{\mathrm{Sc}}$ from all but one CWD elk isolate (\#8) was able to convert human brain $\operatorname{PrP}^{\mathrm{C}}-129 \mathrm{VV}$ into $\operatorname{PrP}^{\text {res }}$ after one round of PMCA, as evidenced by the 3F4-detected $\mathrm{PrP}^{\mathrm{res}}$ in the PMCA products (Fig. 1b). PrP $^{\mathrm{Sc}}$ from the CWD deer was also able to convert human brain $\operatorname{PrP}^{\mathrm{C}}$ into $\mathrm{PrP}^{\text {res }}$ but the efficiency was lower compared to that of CWD elk (Fig. 1b). Moreover, the sPMCA-generated CWD-derived human $\underline{\operatorname{PrP}} \underline{S c}\left(\mathrm{Cd}-\mathrm{HuPrP}^{\mathrm{res}}\right)$ was consistently amplified until round 7 that showed a decrease in the amplification efficiency in both CWD isolates examined (Additional file 1: Fig. S3). Taken together, the results indicate that most of CWD prion isolates examined in this study were able to convert human $\operatorname{PrP}^{\mathrm{C}}-129 \mathrm{~V}$ but not human $\mathrm{PrP}^{\mathrm{C}}-129 \mathrm{M}$ to generate $\mathrm{Cd}-\mathrm{Hu} \mathrm{PrP}^{\text {res }}$ by PMCA in vitro, suggesting a possible polymorphism preference.

\section{Examination of infectivity of CWD-derived human PrPSc by animal transmission assay}

Next we intracerebrally inoculated the $\mathrm{Cd}-\mathrm{HuPrP}{ }^{\text {res }}$ (from the fourth round PMCA seeded the CWD elk \#6 $\mathrm{PrP}^{\mathrm{Sc}}$ seeds in the $\mathrm{PrP}^{\mathrm{C}}$ substrate from the normal human brain homogenate of case $\mathrm{VV \# 1}$ ) into humanized $\mathrm{Tg}$ mice. Two mouse lines were inoculated: one expressing wild-type human PrP-129VV (TgVV) or human PrP-129MM (TgMM, previously termed Tg40h) [20, 26]. All $15 \mathrm{TgVV}$ mice inoculated intracerebrally with $\mathrm{Cd}^{-\mathrm{HuPrP}}{ }^{\mathrm{res}}$ developed disease at an average of $233 \pm 6$ (standard error, SE) days post inoculation (dpi) (range, 195 to $282 \mathrm{dpi}$ ) (Fig. 2). All 9 inoculated TgMM mice developed disease at an average of $552 \pm 27$ dpi (range, 413 to $645 \mathrm{dpi}$ ), a significantly longer incubation time than that of inoculated TgVV mice $(p<0.00001)$ (Fig. 2).

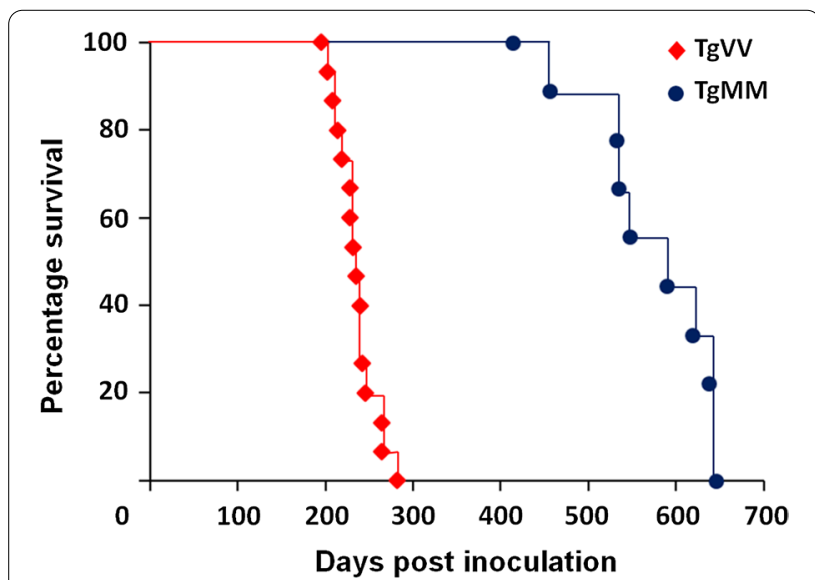

Fig. 2 Kaplan-Meier survival plot for mice of inoculated TgMM or TgW mice. $15 \mathrm{Tg}$ V mice inoculated intracerebrally with diluted sPMCA product succumbed to the disease at an average of $233 \pm 6$ (SE) dpi (range,195 to $282 \mathrm{dpi}$ ) (red diamonds). 9 TgMM mice developed the disease at an average of $552 \pm 27$ (SE) dpi (range, 413 to $645 \mathrm{dpi}$ ) (blue circles), which showed a significantly longer incubation time than that of inoculated TgW mice $(p=8.41465 \mathrm{E}-13<0.00001)$

This is not unexpected since the Cd-HuPrP ${ }^{\text {res }}$ was generated from the human VV\#1 case and prior evidence supports that matching residue 129 between $\operatorname{PrP}^{\mathrm{Sc}}$ and $\operatorname{PrP}^{\mathrm{C}}$ facilitates prion propagation $[19,26]$.

Brains of inoculated Tg mice were examined by western blotting and neurohistology for evidence of $\mathrm{PrP}^{\mathrm{Sc}}$ deposition and spongiform degeneration. We compared the electrophoretic gel profiles of $\mathrm{PrP}^{\text {res }}$ from both $\mathrm{Tg}$ mouse lines inoculated with $\mathrm{Cd}-\mathrm{HuPrP}{ }^{\text {res }}$ after treatment of brain homogenates with a range of PK concentrations $(0,5,25,50$, or $100 \mu \mathrm{g} / \mathrm{mL})$. Interestingly, the gel mobility of $\mathrm{PrP}^{\text {res }}$ from the two lines of infected animals was different, in that TgVV displayed type 2-like $\mathrm{PrP}^{\mathrm{res}}$ and TgMM exhibited type 1-like PrP ${ }^{\text {res }}$; however, the ratio of the diglycosylated to non-glycosylated $\mathrm{PrP}^{\text {res }}$ species was significantly higher in $\mathrm{Cd}-\mathrm{HuPrP}{ }^{\text {res }}$-infected TgMM and TgVV mice (Fig. 3, Additional file 1: Fig. S4), when compared to their SCJD counterparts PrP ${ }^{\text {res }}$ type 1 [9] [2.9 $(\mathrm{n}=5)$ vs. $0.6(\mathrm{n}=3), p<0.001]$ and PrP ${ }^{\text {res }}$ type 2 [42] [2.1 $(\mathrm{n}=7)$ vs $0.1(\mathrm{n}=3), p<0.001]$ (Additional file 1: Fig. S4).

The major histopathological differences between the two lines of inoculated mice were the significantly more severe cortical spongiform degeneration (SD) and the presence of plaque deposits in TgVV mice, compared with TgMM mice (Fig. 4a, b). The plaques were visualized on hematoxylin-eosin stained slides and confirmed to be composed of PrP by IHC staining with anti-PrP antibody 3F4 (Fig. 4a). Notably, occasional plaques were surrounded by vacuoles (Fig. 4a and Additional file 1: Fig. S5), resembling the florid plaques of CWD-affected 


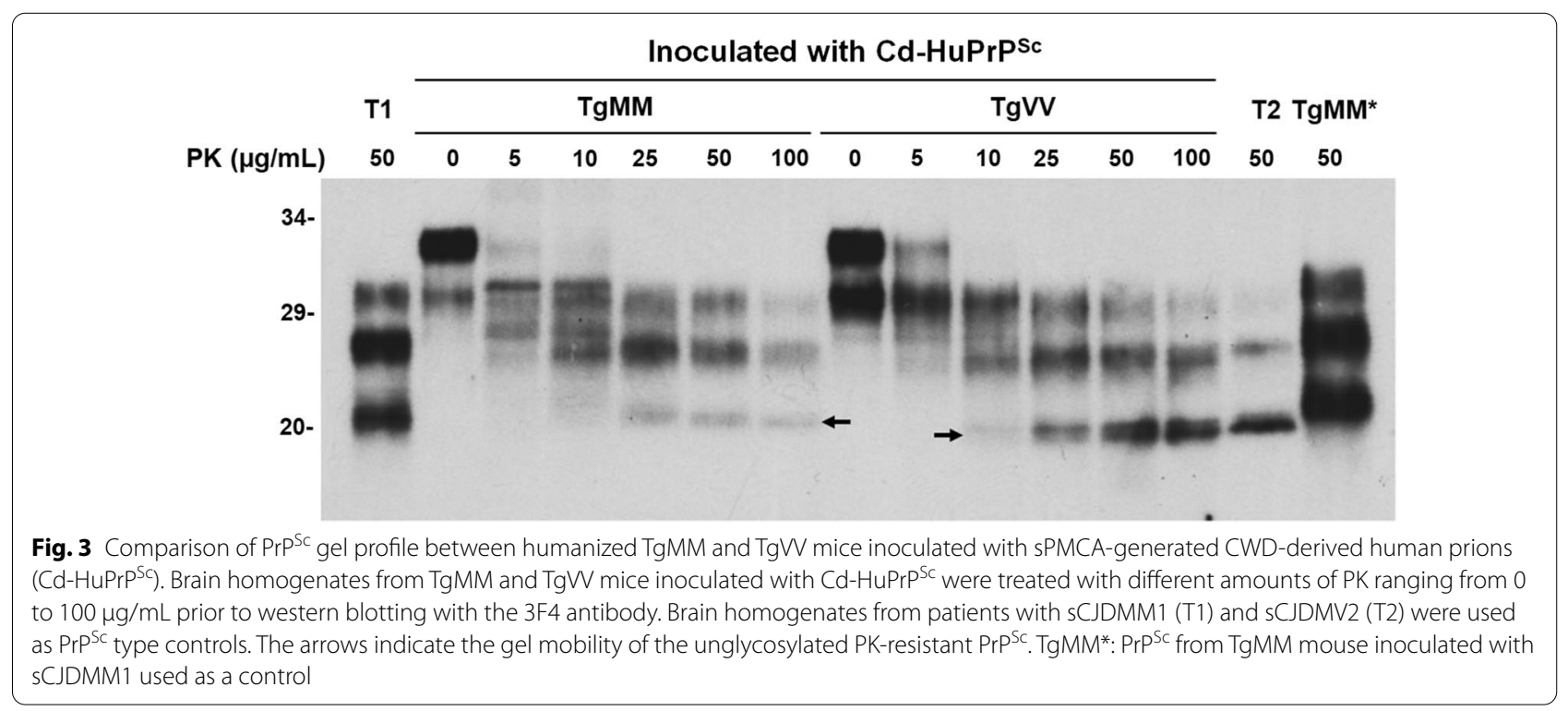

cervids [24]. IHC staining also revealed granular $\mathrm{PrP}^{\mathrm{Sc}}$ deposits that co-distributed with SD. Unlike TgVV mice, TgMM mice were free of plaque-like deposits in the cerebral cortex (CC). Lesion profiling showed similar SD distributions in the two groups of mice, except for the sparse presence of vacuoles in the cerebral cortex and overall less severe SD in the TgMM mice (Fig. 4c). Among the diseased $\mathrm{TgVV}$ mice, more severe lesions were found in animals bearing plaques than in those that were free of plaques (Fig. 4d). Moreover, in comparison with mice expressing matched PrP codon 129 genotypes but inoculated with sCJD prions $[9,42]$, the $\mathrm{Cd}-\mathrm{HuPr} \mathrm{P}^{\text {res }}$-infected $\mathrm{TgVV}$ and TgMM mice showed distinctive histopathological features. These features included (1) the presence of plaques reminiscent of CWD-florid plaques in some $\mathrm{Cd}$ $\mathrm{HuPrP} \mathrm{P}^{\text {res }}$-infected TgVV mice; (2) seemingly more severe cortical spongiosis in $\mathrm{Cd}-\mathrm{HuPrP} \mathrm{P}^{\text {res }}$-infected $\mathrm{TgVV}$ mice than in sCJDVV2-infected TgVV mice [9]; (3) lack of PrP plaques in our $\mathrm{Cd}-\mathrm{HuPrP}{ }^{\text {res }}$-infected $\mathrm{TgMM}$ mice but not in SCJDVV2-infected TgMM mice [9]; and (4) quite distinct lesion profiles between $\mathrm{Cd}-\mathrm{HuPrP}{ }^{\text {res }}$-infected TgMM mice and sCJDMM1-infected TgMM mice [42]. These data demonstrate that $\mathrm{Cd}-\mathrm{HuPrP} \mathrm{P}^{\text {res }}$ is infectious and capable of inducing bona fide prion diseases in mice. We will term it as "Cd-HuPrP $\mathrm{Sc}^{\mathrm{Sc}}$ from here on.

It is conceivable that the sPMCA-generated infectivity in the above experiments could have resulted from de novo generation of PK-sensitive prions produced by sPMCA from the normal human brain homogenate VV\#1 substrate rather than from CWD-seeded human PrP conversion. To rule out this possibility, we determined whether sPMCA induced an increase in the level of the insoluble PrP compared to that of normal brain homogenate substrate without PMCA treatment. We found that 4 rounds of sPMCA in the absence of CWD seeds actually led to a slight decrease of insoluble $\operatorname{PrP}$

\footnotetext{
(See figure on next page.)

Fig. 4 Hematoxylin and Eosin (H\&E) staining and PrP immunohistochemistry (IHC). a, H\&E (upper panels) \& IHC (lower panels) staining of brain sections of TgVV mice inoculated with sPMCA-generated CWD-derived human PrPSC (Cd-HuPrPSc). Upper left panel: Spongiform degeneration (SD) preferentially affecting the deep layers of the cerebral cortex (CC). Upper right panel: Cortical eosinophilic plaque surrounded by vacuoles; inset: PrP IHC of the plaque shown in the upper right panel; the rim of the plaque was more heavily stained than its core. Lower left panel: PrP granules (arrowhead) accumulating mainly in the deep cortical layers. Lower right panel: Granular PrP inside and around the perikarya and processes (arrow) and plaque-like PrP deposits (arrowhead). b. H\&E (upper panels) \& IHC (lower panels) staining of brain sections of TgMM mice inoculated with sPMCA-derived human CWD prions. Upper left panel: SD (arrow) affecting less severely CC than thalamus (Upper right panel); inset in Upper left panel: higher magnification of SD. Lower left panel: Granular PrP deposits affecting the thalamus; Lower right panel: Pattern of PrP deposition similar to those shown in TgVV mice (Lower left panel in a) affecting the ventral midbrain. Bar size: $50 \mu \mathrm{m}$; antibody: 3F4. c, Profiles of brain distribution and severity of SD in the two Tg mouse lines challenged with $\mathrm{Cd}$-HuPrpres were virtually identical, except for more severe lesions in the CC of TgVV mice. d, More severe lesions correlated with the presence of PrP plaques in TgV mice; ${ }^{*} \mathrm{P}<0.05-0.03,{ }^{* * *} \mathrm{P}<0.006$. HI: hippocampus, BG: basal ganglia, TH: thalamus, dMB and vMB: dorsal (d) and ventral (v) midbrain (MB), BS.i.: brainstem, inferior, CE: cerebellum. PrP pl.: PrP plaques; w/o: without. Each point of the lesion profile was expressed as mean \pm standard error of the mean. Statistical significance was determined by a two-tailed Student's t-test
} 


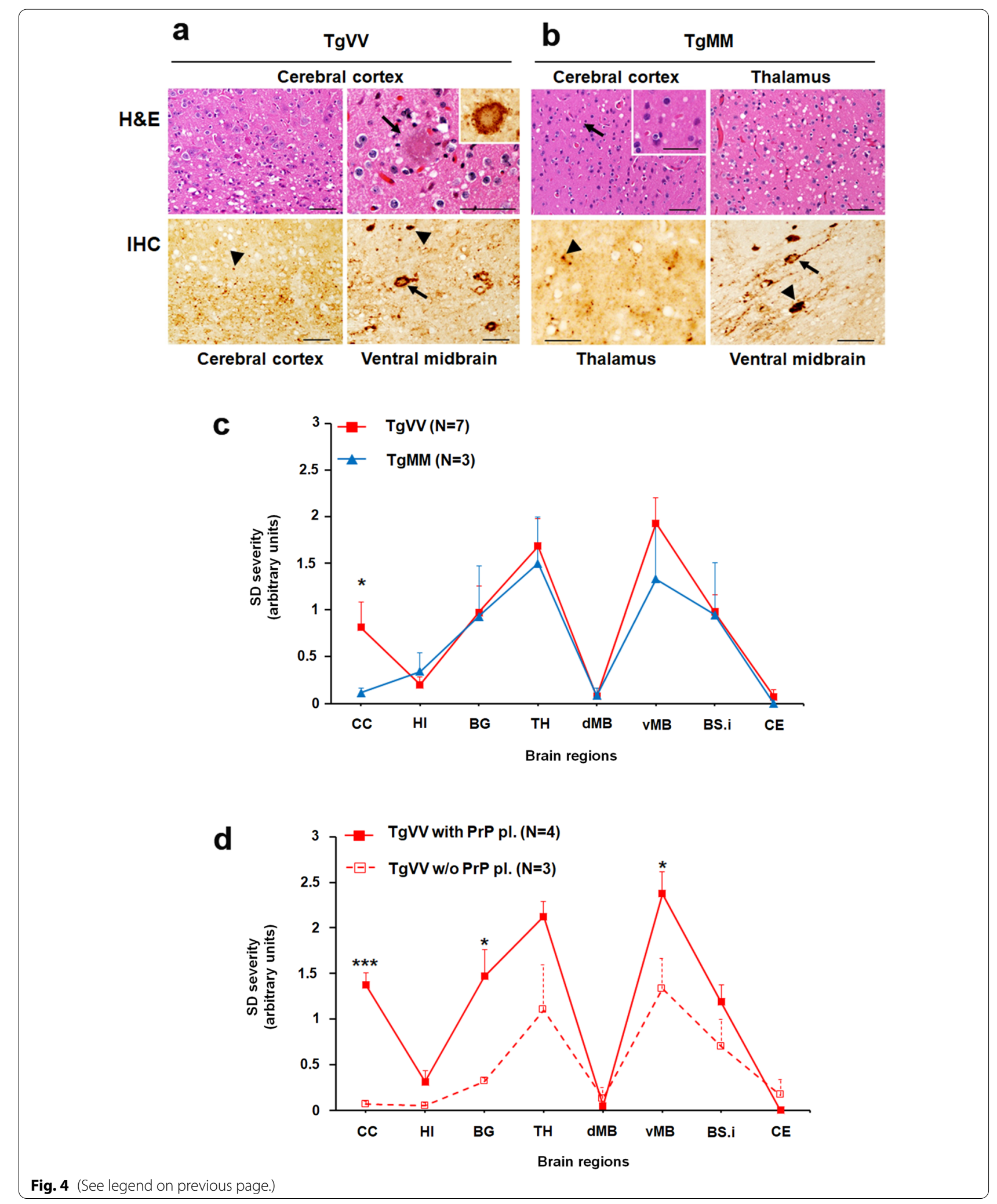


in the P2 fraction and no detectable PK-resistant $\mathrm{PrP}^{\mathrm{Sc}}$ (Additional file 1: Fig. S6), strongly suggesting that the observed infectivity of CWD-seeded sPMCA products in humanized mice was highly unlikely to be due to de novo generation of PK-sensitive $\operatorname{PrP}^{\mathrm{Sc}}$.

\section{Discussion}

Our current study has made the following findings. First, PMCA reveals that elk or deer CWD prions are able to overcome species barrier directly converting human brain $\operatorname{PrP}^{\mathrm{C}}$ carrying $129 \mathrm{~V}$ but not $129 \mathrm{M}$ polymorphism into $\mathrm{PrP}^{\mathrm{Sc}}$ in vitro. Second, the PMCA-induced CWDderived human $\mathrm{PrP}^{\mathrm{Sc}}$ conformer $\left(\mathrm{Cd}-\mathrm{HuPrP}{ }^{\mathrm{Sc}}\right)$ is infectious, as it induced clinical prion disease in two lines of humanized $\mathrm{Tg}$ mice expressing human $\operatorname{PrP}$ with either $129 \mathrm{~V}$ or $129 \mathrm{M}$. Finally, $\operatorname{PrP}^{\mathrm{Sc}}$ in brains of the diseased humanized Tg mice exhibits the electrophoretic mobility similar to those of SCJDMM1 or SCJDVV2 subtype, but the $\mathrm{PrP}^{\mathrm{Sc}}$ glycoform ratios and neuropathological patterns are different. Histopathologically, the $\mathrm{Cd}-\mathrm{HuPrP} \mathrm{Pc}_{-}$ infected TgVV and TgMM mice showed some distinctive features when compared to the $\mathrm{Tg}$ mice expressing the matched 129 genotypes but inoculated with SCJDMM1 or sCJDVV2 prions $[9,42]$. Our findings raise several important issues and implications as to the potential transmissibility of CWD to humans involving effects of seeds and substrates on transmissibility as well as clinical phenotypes of human CWD and traits of CWD-derived human prion strains.

PMCA has been used not only for detection of small amounts of $\mathrm{PrP}^{\mathrm{Sc}}$ in peripheral tissues and various body fluids of suspected prion-infected individuals but also for generation of new $\operatorname{PrP}^{\mathrm{Sc}}[11,12,15,39,40]$, Moreover, it has been applied to explore the potential for cross-species conversion of $\operatorname{PrP}^{\mathrm{C}}$ to $\mathrm{PrP}^{\text {res }}$ as a way to assess the susceptibility of human $\operatorname{PrP}^{\mathrm{C}}$ to animal prion strains including CWD prions $[2,10,17,22]$. Using PMCA, an earlier study revealed that wild-type human $\operatorname{PrP}^{\mathrm{C}}-129 \mathrm{MM}$ from humanized $\mathrm{Tg}$ mice was converted into human $\mathrm{PrP}^{\text {res }}$, but only after the CWD prion isolate had been stabilized by successive passages in cervid brain homogenates [4]. Moreover, the newly-generated $\operatorname{PrP}^{\text {res }}$ had unique biochemical properties with a glycoform pattern similar to CWD seeds but slower migration compared to the seeds. Subsequently, Barria et al. observed that elk CWD prions could convert $\operatorname{PrP}^{\mathrm{C}}$ from human brain, humanized Tg mouse brain and cultured mammalian cells [2]. They also observed that the efficiency of in vitro cell-free human $\operatorname{PrP}$ conversion by cervid CWD prions was influenced by the PrP polymorphism at residue 129 in humans and its equivalent (residue 132) in cervids [3]. However, another study observed that mule deer $\mathrm{PrP}^{\mathrm{Sc}}$ was unable to convert human $\mathrm{PrP}^{\mathrm{C}}$ from humanized Tg mouse brain homogenates [23].
PMCA under properly optimized conditions has been believed to faithfully amplify prions from different species in vitro [29]. The parental prion seed strain traits have been observed to remain in the PMCA amplified prion products [11]. PMCA has become a useful approach to address fundamental questions about prion biology in vitro such as the molecular basis of the seeding activity, some aspects of species barrier and prion strain adaptation, and the role of cofactors on prion replication. It has been also used to assess the zoonotic potential of animal prion diseases such as BSE, scrapie, CWD, and atypical prion diseases. For instance, studies have confirmed that PMCA exhibits species specificity that faithfully reflects the same transmission barrier observed in animals in vivo $[1,10,16,28]$. When BSE and scrapie were examined for their capability to convert human $\operatorname{PrP}$ with the three major polymorphic variants (PRNP codon $129 \mathrm{MM}, \mathrm{MV}$ and VV) expressed in the humanized transgenic mouse brain $[5,17]$, cattle BSE prions was able to trigger the efficient conversion of human PrP with a preference similar to that of human $\mathrm{VCJD}(\mathrm{MM}>\mathrm{MV}>\mathrm{VV})$ while scrapie failed to convert the human substrates [17]. These results suggest that PMCA can faithfully replicate aspects of cross-species transmission potential and might provide useful additional information concerning the molecular barrier to zoonotic transmission. Therefore, although in vitro seeded $\operatorname{PrP}^{\mathrm{Sc}}$ amplification by PMCA may not mimic all aspects of in vivo conversion of brain $\operatorname{PrP}^{\mathrm{C}}$ into $\mathrm{PrP}^{\mathrm{Sc}}$, our finding of the CWD-induced conversion of human brain $\operatorname{PrP}^{\mathrm{C}}$ into $\operatorname{PrP}^{\mathrm{Sc}}$ suggests the potential of transmission of CWD to humans. It may also provide a model to dissect the mechanisms or factors that may be involved in the potential conversion of human $\operatorname{PrP}^{\mathrm{C}}$ into $\operatorname{PrP}^{\mathrm{Sc}}$ by the CWD prions.

The new $\mathrm{Cd}-\mathrm{HuPrP} \mathrm{P}^{\mathrm{Sc}}$ generated by seeding CWD isolates in human $\operatorname{PrP}^{\mathrm{C}}-129 \mathrm{VV}$ exhibits a PrP electrophoretic profile similar to that of the CWD $\mathrm{PrP}^{\mathrm{Sc}}$ seeds that are observed to exhibit a more pronounced di-glycosylated $\operatorname{PrP}$ glycoform but an underrepresented unglycosylated PrP migrating at $\sim 21 \mathrm{kDa}$ [43]. Interestingly, it remains as the $\operatorname{PrP}^{\mathrm{Sc}}$ type 1-like form when it is inoculated into the humanized TgMM mice, whereas it switches into the $\operatorname{Pr} \mathrm{P}^{\mathrm{Sc}}$ type 2-like form when it is inoculated into the humanized TgVV mice. This phenomenon is consistent with the previous findings that $\operatorname{PrP}^{\mathrm{Sc}}$ type 2 was only detected in Tg mice expressing human PrP-129 V inoculated with $\operatorname{PrP}^{\mathrm{Sc}}$ SCJDMV2 or SCJDVV2 while only $\operatorname{PrP}^{\mathrm{Sc}}$ type 1 was detected in mice homozygous or heterozygous for Met at residue 129 regardless of inoculated $\mathrm{PrP}^{\mathrm{Sc}}$ types [7]. Moreover, $\mathrm{PrP}^{\mathrm{C}}-129 \mathrm{MM}$ substrates from two individual non-CJD human brain samples were not able to be converted by CWD prions in PMCA reactions, which contrasts with the observations of Barria et al. [2]. One possible explanation 
is that there are other co-factors or inhibitors affecting the PrP convertibility in the brain tissues of some subjects. This is consistent with the observations that although millions of people are believed to have been exposed to BSE-contaminated products in the European countries, especially in the UK, there were only about 229 vCJD cases reported worldwide as of 2015 [25]. It will be interesting to determine the convertibility of brain $\mathrm{PrP}^{\mathrm{C}}$ from more normal human subjects including all three PrP genotypes (129MM, 129VV and $129 \mathrm{MV})$.

The conversion efficiency varied between CWD prion isolates. Of the eight CWD isolates tested in this study, the seeding efficiency of \#5 and \#2 were the highest, followed by \#6 and \#1, then \#7, \#9, and the lowest were \#8 and \#3. Notably, match or mismatch between residue 129 of the human PrP substrate and residue 132 of the elk $\mathrm{PrP}^{\mathrm{Sc}}$ seeds has been observed to affect the conversion efficiency in PMCA [3]. It will be important to further characterize the effect of different polymorphisms in CWD prion seeds and human $\operatorname{PrP}^{C}$ substrates on the conversion efficiency. Except for the difference in conversion efficiency, no other significant differences were detected in the electrophoretic gel profile of $\mathrm{Cd}-\mathrm{HuPrP} \mathrm{P}^{\mathrm{Sc}}$ derived from different CWD isolates.

Although our study clearly shows that CWD prions are capable of converting human $\mathrm{PrP}^{\mathrm{C}}$ into infectious $\mathrm{PrP}^{\mathrm{Sc}}$ in vitro, the real-world implications are less clear due to several factors. First, the CWD-induced conversion of human $\operatorname{PrP}^{\mathrm{C}}$ into $\mathrm{PrP}^{\mathrm{Sc}}$ was facilitated by repeated rounds of sonication in the PMCA procedure, which is unnatural. Second, in vivo prion clearing and selection mechanisms do not exist in the PMCA reactions, potentially making it easier for the newly converted $\mathrm{PrP}^{\mathrm{Sc}}$ (including those that may be normally selected against in vivo) to persist and amplify in vitro. This could lead to the generation of $\mathrm{PrP}^{\mathrm{Sc}}$ that is different from $\mathrm{PrP}^{\mathrm{Sc}}$ generated in humanized mice after direct inoculation with brain homogenate from a CWD infected deer. Third, the PMCA substrates were derived from brain homogenates of only 4 non-CJD cases with PrP-129MM or $-129 \mathrm{VV}$. Finally, only a few CWD isolates from a limited number of cervid PRNP genotypes were examined. This makes it difficult to draw conclusions on the impact that other CWD strains and PRNP polymorphisms may have on the ability to convert human $\operatorname{PrP}^{\mathrm{C}}$. More research will be needed to address these limitations.

In summary, our study demonstrates that CWD prions are able to cross the species barrier to convert human brain $\mathrm{PrP}^{\mathrm{C}}$ into infectious $\mathrm{PrP}^{\mathrm{Sc}}$ in vitro. Although the $\mathrm{Cd}-\mathrm{HuPrP}{ }^{\mathrm{Sc}}$ largely retains the glycoform pattern of the CWD prion seeds, they produced type $1 \mathrm{PrP}^{\text {res }}$ in the TgMM mice and type 2 PrP $^{\text {res }}$ in the TgVV mice, but with distinct $\mathrm{PrP}^{\mathrm{Sc}}$ glycoform ratios and histopathological features. We believe that our findings establish a new venue to study the likely molecular and neuropathological features of potential acquired human CWD cases, which may provide critical clues for identification of the first human cases of CWD infection should they occur.

\section{Supplementary Information}

The online version contains supplementary material available at https://doi. org/10.1186/s40478-021-01262-y.

Additional File 1: Fig. S1. Western blot analysis of PMCA-generated CWD-derived human $\operatorname{PrP}^{\mathrm{SC}}\left(\mathrm{Cd}-\mathrm{HuPrP}^{\mathrm{SC}}\right)$ probed with 6D11 and 3F4. Representative Western blotting of the PK-treated $(100 \mu \mathrm{g} / \mathrm{mL})$ products of 4 rounds of sPMCA that was conducted with $(+)$ or without $(-)$ CWD isolate \#7 seeds in the normal human brain homogenates with PrP-129VV (V\#1) probing with $6 \mathrm{D} 11$ (a) and 3F4 (b), respectively. The first lane is $\operatorname{PrP}^{C}$ from the normal human brain homogenate used as the substrate in SPMCA while the last lane is the PrPSc from the brain of CWD infected elk used as the seed. Both were directly loaded into the gel as the controls. Fig. S2. Western blot analysis of de novo generation of PK-resistant PrPsc by serial PMCA in the presence of PrPC substrate from different species. Representative western blotting of PK-treated $(100 \mu \mathrm{g} / \mathrm{mL})$ products of sPMCA that was conducted with normal brain homogenates from different species in the absence of PrPSc seeds. The normal brain homogenates were from non-CJD cadaver brain tissues with PrP polymorphism methionine (M)/M $(\mathrm{n}=2, \mathrm{MM} \# 1$ and $M M \# 2)$ or valine $(\mathrm{V}) \mathrm{N}(\mathrm{n}=2, \mathrm{~V} \# 1$ and $\mathrm{V} \# 2)$ at codon 129 of human PrP gene (PRNP), hamster, cervidized Tg mice (TgDeer) and humanized Tg mice (TgMM and TgV). $\mathbf{a}$ and $\mathbf{b}, 1-4$ rounds of sPMCA products with brain homogenates of MM\#1, MM\#2, V\#\#1, W\#2, hamster, TgMM, TgVV and TgDeer as the substrate, respectively. C, 5-8 rounds of sPMCA with brain homogenates of MM\#1, MM\#2, W\#1, W\#2, hamster, TgMM, and TgW as the substrate, respectively. $\mathbf{d}, 9-12$ rounds of SPMCA with brain homogenates of TgVV, MM\#1, MM\#2, W\#1, and W\#2 as the substrate, respectively. Blots were probed with the 3F4 antibody. Fig. S3. Western blot analysis of PMCA-generated CWD-derived human PrPSC $(\mathrm{Cd}-\mathrm{HuPrPS})$. Representative Western blotting of the PK-treated $(100 \mu \mathrm{g} /$ $\mathrm{mL}$ ) products of 2 to 7 rounds of sPMCA that was conducted by seeding CWD isolate \#5 or \#2 in the normal human brain homogenates with PrP$129 \mathrm{~V}$, respectively. The blot was probed with the 3F4 antibody. Fig. S4. Western blot analysis of PrPSc from TgMM and TgV mice inoculated with PMCA-generated CWD-derived human $\operatorname{PrP}^{\mathrm{SC}}\left(\mathrm{Cd}-\mathrm{HuPrP}{ }^{\mathrm{SC}}\right)$. Representative Western blotting of PrPSc from brain homogenates of TgMM (a, \#6145-1, \#6146-2, \#6146-3, \#6146-4, and \#6147-4) and TgW (b, \#1, \#2, \#3, \#5, \#7, $\# 109$, and \#1 10) treated with PK $(50 \mu \mathrm{g} / \mathrm{mL})$. Brain homogenates from patients with sCJDMM1 (T1) and SCJDMV2 (T2) were used as PrPSC type controls. Neg: human brain homogenate without PK-treatment while other samples were all treated with PK at $50 \mu \mathrm{g} / \mathrm{mL}$. The blot was probed with the 3F4 antibody. Fig. S5. Plaque and plaque-like PrP formations in TgVV mice. a H.E. depicting a plaque (arrow) surrounded by vacuoles. b PrP IHC showing plaque-like PrP deposits (arrowhead). Bar size: $50 \mu \mathrm{m}$; antibody: 3F4. Fig. S6. Western blotting of PrP from S2 and P2 fractions after ultracentrifugation of sPMCA products. The products of 4 rounds of sPMCA with the CWD prion isolate (\#7) seeds (lanes 5 and 6) or without seeds (lanes 3 and 4 ) in the presence of normal human brain homogenate (V\#1) were subjected to ultracentrifugation in 5\% lysis buffer at 100,000 $\mathrm{g}$ for $1 \mathrm{~h}$ at $4{ }^{\circ} \mathrm{C}$ to obtain supernatant (S2) and pellet (P2) fractions prior to Western blotting with 3F4 before (a) and after (b) treatment with PK at $100 \mu \mathrm{g} / \mathrm{mL}$. The normal human brain homogenate without seeds and sPMCA was used as a control in lanes 1 and 2.

\section{Acknowledgements}

We thank all donors for brain tissues and the families affected by CJD as well as physicians for support. We thank Dr. Tracy Nichols from the United States Department of Agriculture, Animal and Plant Health Inspection Service, Fort Collins, Colorado, for providing most of the elk CWD isolates, Dr. Glenn Telling for providing brain tissues of TgDeer, and the National Prion Disease Pathology 
Surveillance Center, Case Western Reserve University for providing the brain tissues from SCJD patients and normal controls. This research was funded in part by National Institutes of Health (NIH) R01NS109532 to W.Q.Z. and Q.K., NIH U01NS1 12010 to W.Q.Z., NIH R01NS088604 to Q.K., CJD Foundation to W.Q.Z., and ALZ/ARUK/MJFF/Weston to W.Q.Z, the Brain Research Foundation and support from the Kohn family to J.M., NIH K99AG068359 to I.C. As a trainee of the research education component of the Cleveland Alzheimer's Disease Research Center, the work of I.C. was in part supported by the NIA 5P30AG062428.

\section{Authors' contributions}

W.Q.Z. conceived the study. Z.W., Q.K., J.M. and W.Q.Z. designed the study. Z.W., K.Q., M.V.C., I.C., P.S., J.Y. Q.K. J.M. and W.Q.Z. performed experiments and interpreted data analyses. J.G. provided CWD brain samples. Z.W., I.C., Q.K., J.M. and W.Q.Z. wrote the first version of the paper. All authors critically reviewed, revised, and approved the final version of the manuscript.

\section{Availability of data and material}

All materials used in this study will be made available subject to a material transfer agreement.

\section{Declarations}

\section{Ethics approval and consent to participate}

The use of autopsy human brain tissues was authorized by the Institutional Review Board of University Hospital Cleveland Medical Center and Case Western Reserve University (CWRU), Cleveland, Ohio. The written informed consents by the patients during life or their next of kin after death were received for each case through the National Prion Disease Pathology Surveillance Center (NPDPSC), CWRU, Cleveland, Ohio, for research on brain samples. Post mortem examinations, if permission was available, were carried out in NPDPSC. All information was analyzed anonymously. Animal experiment was performed following a protocol reviewed and approved by the Institutional Animal Care and Use Committee of CWRU and Case Medical Center, Cleveland, Ohio, and University of Chicago, Illinois, USA.

\section{Consent for publication}

The manuscript contains no any individual person's data in any form.

\section{Competing interests}

The authors report no competing interests.

\section{Author details}

'Department of Pathology, Case Western Reserve University School of Medicine, Cleveland, OH 44106, USA. ${ }^{2}$ Department of Neurology and Center for Comprehensive Care and Research On Memory Disorders, The University of Chicago Pritzker School of Medicine, Chicago, IL, USA. ${ }^{3}$ Virus and Prion Research Unit, Agricultural Research Service, National Animal Disease Center, USDA, 1920 Dayton Avenue, Ames, IA 50010, USA. ${ }^{4}$ Department of Neurology, Case Western Reserve University School of Medicine, Cleveland, $\mathrm{OH} 44106$, USA. ${ }^{5}$ National Prion Disease Pathology Surveillance Center, Case Western Reserve University School of Medicine, Cleveland, OH 44106, USA. ${ }^{6}$ National Center for Regenerative Medicine, Case Western Reserve University School of Medicine, Cleveland, OH 44106, USA.

\section{Received: 16 August 2021 Accepted: 8 September 2021}

Published online:

\section{References}

1. Arshad H, Bourkas MEC, Watts JC (2020) The utility of bank voles for studying prion diseases. Prog Mol Biol Transl Sci 175:179-211. https://doi. org/10.1016/Bs.Pmbts.2020.08.009

2. Barria MA, Balachandran A, Morita M, Kitamoto T, Barron R, Manson J et al (2014) Molecular barriers to zoonotic transmission of prions. Emerg Infect Dis 20(1):88-97. https://doi.org/10.3201/eid2001.130858

3. Barria MA, LiboriA MG, Head MW (2018) Susceptibility of human prion protein to conversion by chronic wasting disease prions. Emerg Infect Dis 24(8):1482-1489. https://doi.org/10.3201/eid2408.161888
4. Barria MA, Telling GC, Gambetti P, Mastrianni JA, Soto C (2011) Generation of a new form of human $\operatorname{PrP}(\mathrm{Sc})$ in vitro by interspecies transmission from cervid prions. J Biol Chem 286(9):7490-7495. https://doi.org/10.1074/jbc. M110.198465

5. Barria MA, Ironside JW, Head MW (2014) Exploring the zoonotic potential of animal prion diseases: in vivo and in vitro approaches. Prion 8(1):85-91. https://doi.org/10.4161/pri.28124

6. Benestad SL, Mitchell G, Simmons M, Ytrehus B, Vikøren T (2016) First case of chronic wasting disease in Europe in a Norwegian free-ranging reindeer. Vet Res 47(1):88. https://doi.org/10.1186/s13567-016-0375-4

7. Bishop MT, Will RG, Manson JC (2010) Defining sporadic Creutzfeldt-Jakob disease strains and their transmission properties. Proc Natl Acad Sci U S A 107(26):12005-12010. https://doi.org/10.1073/pnas.1004688107

8. Brown P (2013) Environmentally-acquired transmissible spongiform encephalopathy. In: Zou WQ, Gambetti P (eds) Prions and diseases, 1st edn. Springer, New York, pp 73-88

9. Cali I, Espinosa JC, Nemani SK, Marin-Moreno A, Camacho MV, Aslam $R$ et al (2021) Two distinct conformers of PrPD type 1 of sporadic Creutzfeldt-Jakob disease with codon 129V genotype faithfully propagate in vivo. Acta Neuropathol Commun 9(1):55. https:/doi.org/10.1186/ s40478-021-01132-7

10. Castilla J, Gonzalez-Romero D, Saá P, Morales R, De Castro J, Soto C (2008) Crossing the species barrier by $\operatorname{PrP}(\mathrm{Sc})$ replication in vitro generates unique infectious prions. Cell 134(5):757-768. https://doi.org/10.1016/j. cell.2008.07.030

11. Castilla J, Saá P, Hetz C, Soto C (2005) In vitro generation of infectious scrapie prions. Cell 121(2):195-206. https://doi.org/10.1016/j.cell.2005.02. 011

12. Castilla J, Saá P, Soto C (2005) Detection of prions in blood. Nat Med 11(9):982-985. https://doi.org/10.1038/nm1286

13. Collinge J, Sidle KC, Meads J, Ironside J, Hill AF (1996) Molecular analysis of prion strain variation and the aetiology of "new variant" CJD. Nature 383(6602):685-690. https://doi.org/10.1038/383685a0

14. Czub S (2017) First evidence of intracranial and peroral transmission of chronic wasting disease (CWD) into Cynomolgus macaques: A work in progress. (Abstract) from Prion 2017, held in Edinburgh, Scotland, May 23-26.

15. Deleault NR, Lucassen RW, Supattapone S (2003) RNA molecules stimulate prion protein conversion. Nature 425(6959):717-720. https://doi.org/ 10.1038/nature01979

16. Green KM, Castilla J, Seward TS, Napier DL, Jewell JE, Soto C, Telling GC (2008) Accelerated high fidelity prion amplification within and across prion species barriers. PLoS Pathog 4(8):e1000139. https://doi.org/10. 1371/journal.ppat.1000139

17. Jones M, Wight D, Barron R, Jeffrey M, Manson J, Prowse C et al (2009) Molecular model of prion transmission to humans. Emerg Infect Dis 15(12):2013-2016. https://doi.org/10.3201/eid1512.090194

18. Kascsak RJ, Rubenstein R, Merz PA, Tonna-DeMasi M, Fersko R, Carp RI et al (1987) Mouse polyclonal and monoclonal antibody to scrapie-associated fibril proteins. J Virol 61(12):3688-3693. https://doi.org/10.1128/JVI.61.12. 3688-3693.1987

19. Kobayashi A, Asano M, Mohri S, Kitamoto T (2007) Cross-sequence transmission of sporadic Creutzfeldt-Jakob disease creates a new prion strain. J Biol Chem 282(41):30022-30028. https://doi.org/10.1074/jbc.M7045 97200

20. Kong Q, Huang S, Zou W, Vanegas D, Wang M, Wu D et al (2005) Chronic wasting disease of elk: transmissibility to humans examined by transgenic mouse models. J Neurosci 25(35):7944-7949. https://doi.org/10. 1523/JNEUROSCI.2467-05.2005

21. Koutsoumanis K, Allende A, Alvarez-Ordoňez A, Bolton D, Bover-Cid S et al (2019) Update on chronic wasting disease (CWD) III. EFSA J 17(11):e05863. https://doi.org/10.2903/j.efsa.2019.5863

22. Krejciova Z, Barria MA, Jones M, Ironside JW, Jeffrey M, González L et al (2014) Genotype-dependent molecular evolution of sheep bovine spongiform encephalopathy (BSE) prions in vitro affects their zoonotic potential. J Biol Chem 289(38):26075-26088. https://doi.org/10.1074/jbc. M114.582965

23. Kurt TD, Jiang L, Fernández-Borges N, Bett C, Liu J, Yang T et al (2015) Human prion protein sequence elements impede cross-species chronic wasting disease transmission. J Clin Invest 125(6):2548. https://doi.org/10. 1172/JCl82647 
24. Liberski PP, Guiroy DC, Williams ES, Walis A, Budka H (2001) Deposition patterns of disease-associated prion protein in captive mule deer brains with chronic wasting disease. Acta Neuropathol 102(5):496-500. https:// doi.org/10.1007/s004010100417

25. Maheshwari A, Fischer M, Gambetti P, Parker A, Ram A, Soto C et al (2015) Recent US case of variant Creutzfeldt-Jakob disease-global implications. Emerg Infect Dis 21(5):750-759. https://doi.org/10.3201/eid2105.142017

26. Mallik S, Yang W, Norstrom EM, Mastrianni JA (2010) Live cell fluorescence resonance energy transfer predicts an altered molecular association of heterologous PrPSC with PrPC. J Biol Chem 285(12):8967-8975. https:// doi.org/10.1074/jbc.M109.058107

27. Marsh RF, Kincaid AE, Bessen RA, Bartz JC (2005) Interspecies transmission of chronic wasting disease prions to squirrel monkeys (Saimiri sciureus). J Virol 79(21):13794-13796. https://doi.org/10.1128/JVI.79.21.13794-13796. 2005

28. Meyerett C, Michel B, Pulford B, Spraker TR, Nichols TA, Johnson T et al (2008) In vitro strain adaptation of CWD prions by serial protein misfolding cyclic amplification. Virology 382(2):267-276. https://doi.org/10. 1016/j.virol.2008.09.023

29. Moda F, Pritzkow S, Soto C (2013) Protein misfolding cyclic amplification. In: Zou WQ, Gambetti P (eds) Prions and diseases, 1st edn. Springer, New York, pp 83-92

30. Osterholm MT, Anderson CJ, Zabel MD, Scheftel JM, Moore KA, Appleby BS (2019) Chronic wasting disease in Cervids: implications for prion transmission to humans and other animal species. mBio 10(4):e01091e010119. https://doi.org/10.1128/mBio.01091-19

31. Priola SA (2013) Species barriers in prion diseases. In: Zou WQ, Gambetti P (eds) Prions and diseases, 1st edn. Springer, New York, pp 139-154

32. Prusiner SB (1998) Prions. Proc Natl Acad Sci U S A 95(23):13363-13383. https://doi.org/10.1073/pnas.95.23.13363

33. Race B, Meade-White KD, Miller MW, Barbian KD, Rubenstein R, LaFauci $\mathrm{G}$ et al (2009) Susceptibilities of nonhuman primates to chronic wasting disease. Emerg Infect Dis 15(9):1366-1376. https://doi.org/10.3201/eid15 09.090253

34. Race B, Meade-White KD, Phillips K, Striebel J, Race R, Chesebro B (2014) Chronic wasting disease agents in nonhuman primates. Emerg Infect Dis 20(5):833-837. https://doi.org/10.3201/eid2005.130778

35. Race B, Williams K, Orrú CD, Hughson AG, Lubke L, Chesebro B (2018) Lack of transmission of chronic wasting disease to cynomolgus macaques. J Virol 92(14):e00550-e618. https://doi.org/10.1128/JVl.00550-18
36. Rivera NA, Brandt AL, Novakofski JE, Mateus-Pinilla NE (2019) Chronic wasting disease in cervids: prevalence, impact and management strategies. Vet Med (Auckl) 10:123-139. https://doi.org/10.2147/NMRR.S197404

37. Sandberg MK, Al-Doujaily H, Sigurdson CJ, Glatzel M, O'Malley C, Powell C et al (2010) Chronic wasting disease prions are not transmissible to transgenic mice overexpressing human prion protein. J Gen Virol 91(Pt 10):2651-2657. https://doi.org/10.1099/vir.0.024380-0

38. Sohn HJ, Kim JH, Choi KS, Nah JJ, Joo YS, Jean YH et al (2002) A case of chronic wasting disease in an elk imported to Korea from Canada. J Vet Med Sci 64(9):855-858. https://doi.org/10.1292/jvms.64.855

39. Wang F, Wang X, Yuan CG, Ma J (2010) Generating a prion with bacterially expressed recombinant prion protein. Science 327(5969):1132-1135. https://doi.org/10.1126/science.1183748

40. Wang Z, Manca M, Foutz A, Camacho MV, Raymond GJ, Race B et al (2019) Early preclinical detection of prions in the skin of prion-infected animals. Nat Commun 10(1):247. https://doi.org/10.1038/s41467-018-08130-9

41. Will RG, Ironside JW, Zeidler M, Cousens SN, Estibeiro K, Alperovitch A et al (1996) A new variant of Creutzfeldt-Jakob disease in the UK. Lancet 347(9006):921-925. https://doi.org/10.1016/s0140-6736(96)91412-9

42. Xiao X, Yuan J, Qing L, Cali I, Mikol J, Delisle MB et al (2014) Comparative study of prions in iatrogenic and sporadic Creutzfeldt-Jakob disease. J Clin Cell Immunol 5(4):240. https://doi.org/10.4172/2155-9899.1000240

43. Xie Z, O'Rourke KI, Dong Z, Jenny AL, Langenberg JA, Belay ED et al (2006) Chronic wasting disease of elk and deer and Creutzfeldt-Jakob disease: comparative analysis of the scrapie prion protein. J Biol Chem 281(7):4199-4206. https://doi.org/10.1074/jbc.M509052200

44. Yuan J, Xiao X, McGeehan J, Dong Z, Cali I, Fujioka H et al (2006) Insoluble aggregates and protease-resistant conformers of prion protein in uninfected human brains. J Biol Chem 281(46):34848-34858. https://doi.org/ 10.1074/jbc.M602238200

45. Zou WQ, Langeveld J, Xiao X, Chen S, McGeer PL, Yuan J et al (2010) PrP conformational transitions alter species preference of a PrP-specific antibody. J Biol Chem 285(18):13874-13884. https://doi.org/10.1074/jbc. M109.088831

\section{Publisher's Note}

Springer Nature remains neutral with regard to jurisdictional claims in published maps and institutional affiliations.
Ready to submit your research? Choose BMC and benefit from:

- fast, convenient online submission

- thorough peer review by experienced researchers in your field

- rapid publication on acceptance

- support for research data, including large and complex data types

- gold Open Access which fosters wider collaboration and increased citations

- maximum visibility for your research: over $100 \mathrm{M}$ website views per year

At BMC, research is always in progress.

Learn more biomedcentral.com/submissions 